\title{
On the Cover: Analysis of Damage and Failure in Anisotropic Ductile Metals Based on Biaxial Experiments with the H-Specimen
}

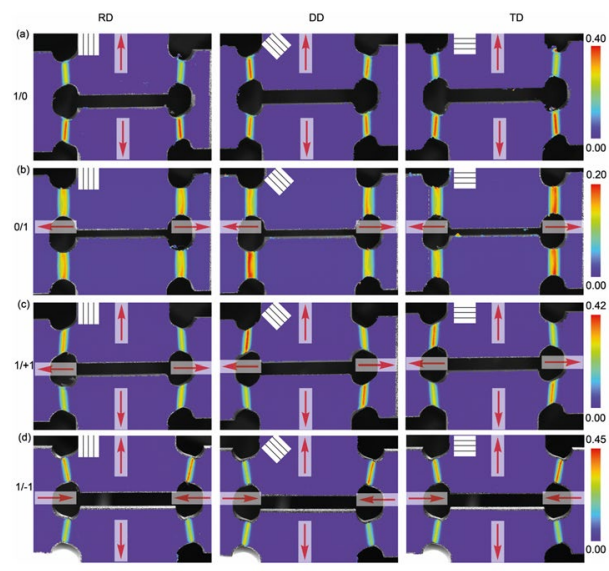

Analysis of Damage and Failure in Anisotropic Ductile Metals Based on Biaxial Experiments with the H-Specimen by M. Brünig, S. Koirala, S. Gerke 